\title{
Studies in the System Magnesia-Silica-Water at Elevated Temperatures and Pressures
}

\author{
Elmer T. Carlson, Richard B. Peppler, and Lansing S. Wells
}

\begin{abstract}
The reactions between magnesia and silica under hydrothermal and pneumalolytic conditions were investigated. Chrysotile and talc were produced, depending on the ratio of the reacting oxides. The chrysotile was submicroscopic but was shown by the electron microscope to have a fibrous structurs. Chrysotile and talc were likewise preparad from mixtures of magnesium carbonate and silica. The same products were obtained by the action of silica in the vapor phase on solid magnesia. A detailed study of this method was made, and the effects of temperature, pressure, time, $\mathrm{pH}$, and oxide ratio on the amount of silica transported were determined. The overall rate of transport was found to increase with temperature, pressure, and $\mathrm{pH}$.
\end{abstract}

\section{Introduction}

The system $\mathrm{MgO}-\mathrm{SiO}_{2}-\mathrm{H}_{2} \mathrm{O}$ has been the subject of extensive study by a considerable number of investigators over a period of many years. This widespread interest is in part due to a desire to explain the mechanism of the formation in nature of the various hydrated magnesium silicate minerals, particularly serpentine. Probably a stronger motive for much of the research has been the hope of developing a method for the practical synthesis of serpentine in its fibrous form, chrysotile, which is the most important of the asbestos minerals.

The various terms applied to the serpentine minerals are not used in the same way by all investigators. In this report no attempt will be made to justify the terminology employed, but the mineral names will be used in accordance with what appears to be most common usage. The word serpentine will be applied in general to the mineral or to synthetic preparations having the approximate composition $3 \mathrm{MgO} \cdot 2 \mathrm{SiO}_{2} \cdot 2 \mathrm{H}_{2} \mathrm{O}$. The terms chrysotile and antigorite will be applied respectively to the fibrous and the platy crystalline forms of serpentine. These two forms presumably differ in their internal structure, but the X-ray patterns that have been published have many features in common, and often are not free from ambiguity.

Magnesia and silica have been found to combine readily in the presence of water vapor, especially at elevated temperatures and pressures. Among the products obtained is a compound having the chemical composition of chrysotile, but never its fibrous habit, so far as can be seen with the light microscope. Bowen and Tuttle [1], ${ }^{1}$ in their study of the system $\mathrm{MgO}-\mathrm{SiO}_{2}-\mathrm{H}_{2} \mathrm{O}$, showed by differential thermal analysis, and other means, that this actually is chrysotile. Electron photomicrographs showed that the crystals were definitely rod shaped. These authors also showed that chrysotile may be formed at temperatures below $500^{\circ} \mathrm{C}$, but not above, and at pressures from 2,000 to $40,000 \mathrm{lb} / \mathrm{in}^{2}$.

1 Figures in brackets indicate the literature references at the end of this paper.
One of the ultimate objects of the present work was the preparation of chrysotile fibers of larger size. This attempt proved unsuccessful, but some of the information obtained appears of sufficient value to be recorded.

As a preliminary step in this investigation, an exhaustive search was made of the literature pertaining to asbestos, as well as to the system $\mathrm{MgO}$ $\mathrm{SiO}_{2}-\mathrm{H}_{2} \mathrm{O}$ and related subjects. A bibliography of selected references has been compiled. ${ }^{2}$

\section{Experimental Studies}

\subsection{Solubility of Magnesia}

As a starting point it was considered desirable to know the solubility of the reactants at elevated temperatures. The solubility of silica in water has already been investigated thoroughly over the range from $0^{\circ}$ to $425^{\circ} \mathrm{C}$, and at pressures up to $1,250 \mathrm{~atm}$. The available data being adequate, no further work was done in this field.

The situation with respect to magnesia is quite different. A considerable number of investigations of the solubility of magnesia at and near room temperature have been made, but the data vary over a wide range. It has peen shown that the solubility of magnesia varies with the temperature at which it was prepared, and varies also if it was prepared at a given temperature from different materials. Gjaldbaek [2], in 1925, concluded that there is an unstable, soluble form of $\mathrm{Mg}(\mathrm{OH})_{2}$ which first forms and is quickly converted to a stable, less soluble form.

There appears to have been only one investigation of the solubility of $\mathrm{Mg}(\mathrm{OH})_{2}$ in the absence of $\mathrm{CO}_{2}$ and at temperatures above the melting point of water. This is the work of Travers and Nouvel [3] in 1929, wherein the solubility of $\mathrm{Mg}(\mathrm{OH})_{2}$ was investigated in the range from $0^{\circ}$ to $200^{\circ} \mathrm{C}$. The description of their method is very brief, and nothing: is said about filtration of high-temperature solutions. It therefore seemed advisable to investigate the

\footnotetext{
${ }^{2}$ A limited number of single $\sim$ pies are available from the authors.
} 


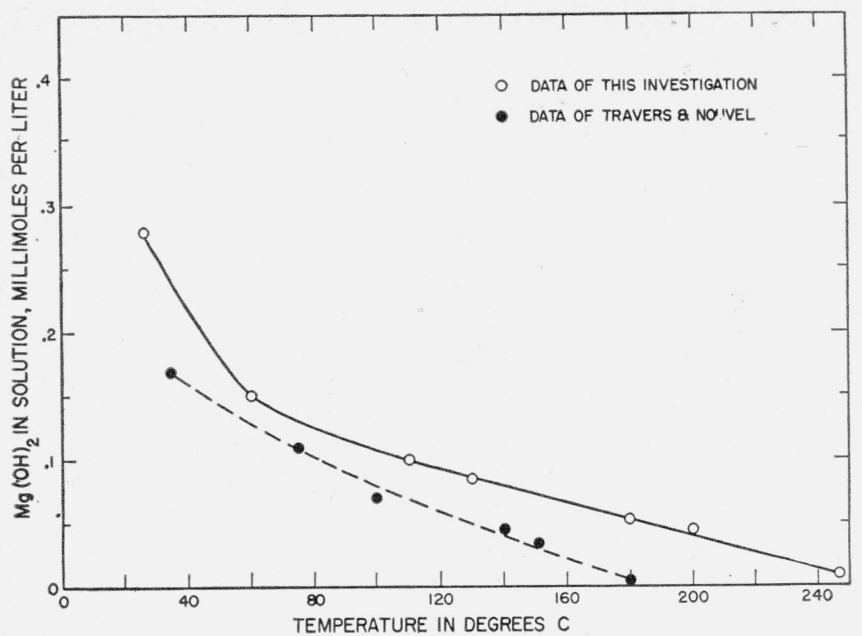

Figure 1. Solubility of magnesia in water at various temperatures.

solubility of magnesia over as wide a temperature range as possible.

The solubility determinations were made on the same $\mathrm{MgO}$ that was used in subsequent synthesis experiments. It was of laboratory quality and had been previously ignited for $1 \mathrm{hr}$ at $1,000^{\circ} \mathrm{C}$. It was found to contain 0.2 percent of extraneous soluble salts. A series of solubility determinations were also made on another portion of this same $\mathrm{MgO}$ that had been extracted with water and that had not been previously ignited. The values obtained with this $\mathrm{MgO}$ were slightly but consistently lower than those obtained with the ignited and unwashed $\mathrm{MgO}$.

The water used in each case was ordinary distilled water, the $\mathrm{CO}_{2}$ content of which had been decreased by boiling and bubbling $\mathrm{CO}_{2}$-free air through it. A few determinations were made, using water that had not been treated in this fashion, and the solubilities thus obtained were consistently slightly higher.

Solubility determinations were made at seven different temperatures in the range $30^{\circ}$ to $250^{\circ} \mathrm{C}$. The determinations at temperatures under $100^{\circ} \mathrm{C}$ were made in rubber-stoppered polyethylene bottles, that were stored, with occasionali shaking, in electrically heated ovens maintained at the desired temperature. Portions of these solutions were taken from time to time and analyzed until a value was obtained that did not change for several days. The $\mathrm{MgO}$ was determined by titration against standard $\mathrm{HCl}$, using methyl red as an indicator.

For the determinations at temperatures above $100^{\circ}$, use was made of an autoclave of special design described in an earlier paper [4]. This autoclave was of stainless steel, with a capacity of 2 liters, and was fitted with a Munroe filter, which permitted filtration of the solution before the autoclave was opened. Aliquots were analyzed as described above.

The data are presented in table 1 and plotted in figure 1. The solubility was found to decrease steadily from $2.1 \times 10^{-4}$ mole per liter at $30^{\circ}$ to $1 \times 10^{-5}$ mole per liter at $250^{\circ}$.
TABLE 1. Solubility of $\mathrm{Mg}(\mathrm{OH})_{2}$ in water at various temperatures

\begin{tabular}{|c|c|c|c|c|}
\hline Experiment & Type of $\mathrm{MgO}$ & $\begin{array}{l}\text { Tempera- } \\
\text { ture }\end{array}$ & Time & $\begin{array}{l}\text { Solubility } \\
\text { as } \mathrm{Mg}(\mathrm{OH})_{2}\end{array}$ \\
\hline $\begin{array}{l}1 \\
2 \\
3 \\
4 \\
5 \\
6 \\
7 \\
8 \\
9\end{array}$ & $\begin{array}{l}\text { Washed } \\
\text { Ignited } \\
\text { Washed } \\
\text { Ignited } \\
\text { do } \\
\text { do } \\
\text { do do }\end{array}$ & $\begin{array}{l}{ }^{\circ} C \\
30 \\
30 \\
60 \\
60 \\
110 \\
130 \\
180 \\
200 \\
245\end{array}$ & $\begin{array}{c}\text { Days } \\
10 \\
4 \\
9 \\
7 \\
10 \\
12 \\
10 \\
10 \\
10\end{array}$ & $\begin{array}{c}\text { Millimole/Liter } \\
0.21 \\
.28 \\
.14 \\
.16 \\
.10 \\
.08 \\
.05 \\
.04 \\
.01\end{array}$ \\
\hline
\end{tabular}

In the determinations at $30^{\circ}$ and at $60^{\circ} \mathrm{C}$ there was an initial supersaturation lasting about a day. When a series of samples at $30^{\circ} \mathrm{C}$ were tumbled continuously on a suitable mechanical tumbler, the duration of the period of supersaturation was greatly reduced but the magnitude remained about the same. Because the actual shape of the solubility-versustime graphs is a function of technique used, they are not reproduced in this paper.

At the lowest temperatures there was an appreciable difference between the data obtained for the washed and for the unwashed ignited magnesia. As the temperature increased, the difference decreased; accordingly, at temperatures above $100^{\circ} \mathrm{C}$, only one kind, the ignited $\mathrm{MgO}$, was used.

In the temperature range $100^{\circ}$ to $250^{\circ} \mathrm{C}$ the solubility of magnesia steadily decreases (fig. 1). The smallest value, $1 \times 10^{-5}$ mole/liter, is the limit of usefulness of this method of analysis, for thereafter the area of confusion in the end point is of the same order of magnitude as the titration.

The data of Travers and Nouvel [3] are also plotted in figure 1. It may be observed that their data are of the same order of magnitude as those obtained in this investigation, but consistently lower. Because these investigators do not describe the magnesia they used nor what precautions, if any, were taken to remove $\mathrm{CO}_{2}$ from the solutions, one cannot comment on this difference.

For the purpose of this investigation it was not considered desirable to extend these solubility determinations to higher temperatures. It is apparent that the solubility of $\mathrm{Mg}(\mathrm{OH})_{2}$ will become immeasurably small before even the minimum temperature of the subsequent synthesis experiments is reached.

\subsection{Synthesis Experiments \\ a. Materials and Methods}

For most of the experimental work the magnesia used was reagent quality magnesium oxide. This was found to be hydrated to a considerable, and variable, extent. Calcium in soluble form was found to be present to the extent of 0.17 percent, expressed as $\mathrm{CaO}$. No attempt was made to determine the actual calcium compounds present. It was not considered necessary to purify the magnesia further by extraction with water. Failure to do so, however, gave rise to some confusing results, to be 
described later. The magnesia was used either in the partially hydrated state or after ignition at selected temperatures.

For a few experiments, reagent quality magnesium carbonate was used. Analysis indicated that it was actually the basic carbonate, hydromagnesite $\left(3 \mathrm{MgCO}_{3} \cdot \mathrm{Mg}(\mathrm{OH})_{2} \cdot 3 \mathrm{H}_{2} \mathrm{O}\right)$.

Several forms of silica, including silica gel, powdered flint, and quartz, were used. For the majority of the experiments the silica was present as reagent grade silicic acid. Ordinary distilled water was used.

Pressure bombs of the Morey type served as reaction vessels. These were made of stainless steel, and had an average capacity of about $18 \mathrm{ml}$. "They were heated in vertical-tube resistance furnaces with pyrometric control, using iron-constantan couples. In most cases the fluctuation in temperature over a period of a week was within a 4-deg range. Pressure was neither independently controlled nor directly measured. The values given for pressure in tables 2,3 , and 4 were calculated from the temperature and the ratio of the quantity of water to the volume of the vessel. The charge was placed in a small platinum crucible supported above the bottom of the bomb. For the vapor-transport experiments, only the magnesia was placed in the crucible, the silica being put in the bomb cavity beneath. In these cases the crucible was left uncovered, and as a rule no water was added directly to the magnesia. Except where otherwise stated, the quantity of water in the bomb was approximately the amount that would be completely converted to steam just below the critical temperature.

After removal from the furnace, the bomb was cooled in air, in front of a fan, and opened. The charge was then dried at about $110^{\circ} \mathrm{C}$, and examined under the polarizing microscope. X-ray diffraction analysis and other tests were then made, if desired. $\mathrm{X}$-ray patterns were made on an X-ray Geigercounter diffractometer, using copper $\mathrm{K}_{\alpha}$ radiation.

\section{b. Experiments with Mixtures of Magnesia and Silica}

Several series of experiments were conducted on intimate mixtures of magnesia and silica, both in the $3: 2$ molar ratio required for serpentine and in the $3: 4$ ratio of talc. Data for a few of these experiments are presented in table 2 , the rest having been omitted because they contributed no additional information of significance.

The reaction products always appeared amorphous when viewed under the microscope, except that there was often some birefringence, especially in products formed at the higher temperatures and in the more siliceous mixtures. The index of refraction was close to 1.56 in all cases. By means of X-ray diffraction patterns it was shown that crystalline material was produced. After 1 day at $200^{\circ} \mathrm{C}$, a mixture of magnesia and silicic acid in $3: 2$ molar ratio gave a very weak diffraction pattern with diffuse bands. Higher temperatures and longer heating periods resulted in stronger patterns. After 7 days at $250^{\circ}$, a strong pattern was $\overline{\$}$ obtained, and similar results were found at higher temperatures.
TABLE 2. Daia of hydrothermal experiments on mixtures of magnesia and silica

\begin{tabular}{|c|c|c|c|c|c|c|}
\hline $\begin{array}{c}\text { Experi- } \\
\text { ment }\end{array}$ & $\begin{array}{c}\text { Molar } \\
\text { ratio } \\
\mathrm{MgO}^{\mathrm{O}} \mathrm{SiO}_{2}\end{array}$ & $\begin{array}{l}\text { Initial state } \\
\text { of } \mathrm{MgO}\end{array}$ & $\begin{array}{l}\text { Tem- } \\
\text { pera- } \\
\text { ture }\end{array}$ & $\begin{array}{l}\text { Pres- } \\
\text { sure }\end{array}$ & Time & Product \\
\hline $1 \ldots$ & $3: 2$ & $\mathrm{MgO}_{2}$ & $\begin{array}{l}{ }^{\circ} \mathrm{C} \\
200\end{array}$ & $\begin{array}{r}\text { atm } \\
15\end{array}$ & $\begin{array}{c}\text { Days } \\
1\end{array}$ & Chrysotile (diffuse \\
\hline $\begin{array}{l}2 \\
3 \\
4 \\
5 \\
-\end{array}$ & $\begin{array}{l}3: 2 \\
3: 2 \\
3: 2 \\
3: 2\end{array}$ & \begin{tabular}{|c}
{$\left[\mathrm{d}_{2}\right.$} \\
$\ldots$ do
\end{tabular} & $\begin{array}{l}250 \\
300 \\
380 \\
412\end{array}$ & $\begin{array}{r}39 \\
85 \\
235 \\
315\end{array}$ & $\begin{array}{l}7 \\
7 \\
7 \\
4\end{array}$ & $\begin{array}{l}\text { Chrysotile. } \\
\text { Do. } \\
\text { Do. } \\
\text { Do. }\end{array}$ \\
\hline 6 & $\begin{array}{l}3: 2 \\
3: 2\end{array}$ & $\mathrm{MgCO}_{3} \mathrm{a}_{\ldots} \ldots$ & $\begin{array}{l}470 \\
348\end{array}$ & $\begin{array}{l}365 \\
159\end{array}$ & $\begin{array}{l}3 \\
7\end{array}$ & Do. \\
\hline $\begin{array}{l}8 \\
9 \\
9\end{array}$ & $\begin{array}{l}3: 2 \\
3: 2\end{array}$ & $\begin{array}{c}\mathrm{do} \\
\mathrm{MgCO}_{3} \\
3 \mathrm{H}_{2} \mathrm{O}^{\mathrm{b}}\end{array}$ & $\begin{array}{l}373 \\
404\end{array}$ & $\begin{array}{l}215 \\
300\end{array}$ & $\begin{array}{r}5 \\
13\end{array}$ & $\begin{array}{l}\text { Chrysotile. } \\
\text { Do. }\end{array}$ \\
\hline $10 \ldots$ & $3: 4$ & $\mathrm{MgO}$ & 301 & 86 & 7 & Talc. \\
\hline $\begin{array}{l}11 \ldots \\
12 \\
13 \\
14 \ldots\end{array}$ & $\begin{array}{l}3: 4 \\
3: 4 \\
3: 4 \\
3: 4\end{array}$ & $\begin{array}{c}\mathrm{do} \\
\mathrm{MgCO} \\
\mathrm{dg}_{3} \mathrm{a} \\
\mathrm{ddo}_{\ldots}\end{array}$ & $\begin{array}{l}368 \\
422 \\
299 \\
419\end{array}$ & $\begin{array}{r}203 \\
315 \\
84 \\
310\end{array}$ & $\begin{array}{l}7 \\
7 \\
7 \\
7\end{array}$ & $\begin{array}{l}\text { Do. } \\
\text { Do. } \\
\text { Do. } \\
\text { Do. }\end{array}$ \\
\hline
\end{tabular}

a Reagent quality magnesium carbonate, found by analysis to be basic magnesium carbonate (hydromagnesite, $3 \mathrm{MgCO}_{3} \cdot \mathrm{Mg}(\mathrm{OH})_{2} \cdot 3 \mathrm{H}_{2} \mathrm{O}$ ).

bynthetic.

In these cases the pattern was essentially identical with one given by a specimen of natural chrysotile asbestos.

Similar results were obtained when magnesium carbonate was substituted for magnesium oxide in the mixtures. The silica displaced the $\mathrm{CO}_{2}$ from the carbonate.

Mixtures of magnesia and silica in 3:4 ratio produced talc at all temperatures tried.

In a series of experiments with the $3: 2$ mixture, very small amounts of various other substances were added. These included compounds of various metals that are known to occur in natural serpentine, also ammonia, ammonium salts, volatile acids, and $\mathrm{NaOH}$. In no case was there any evidence of fibrous structure in the product.

\section{c. Vapor Transport Experiments}

It has been shown that silica is appreciably soluble in water-vapor, both above and below the critical temperature. Synthesis of serpentine through the action of vapor-borne silica on $\mathrm{Mg}(\mathrm{OH})_{2}$ has been reported by Syromyatnikov [5] and van Nieuwenburg [6]. It appeared desirable to make a study of this method of synthesis, with special attention to the effect of temperature and various other conditions on the rate of transport of silica.

For these experiments a weighed quantity of $\mathrm{MgO}$ was placed in a small open crucible supported near the top of the bomb chamber, and the silica and water were placed in the bottom of the chamber. After the desired period of heating, the crucible and contents were removed, dried, ignited at $1,100^{\circ} \mathrm{C}$, and weighed. The increase in weight was ascribed to $\mathrm{SiO}_{2}$. In one case the silica was determined by actual analysis, with good agreement as to results.

An attempt was made to evaluate separately the effects of relative proportion of the oxides, temperature, pressure, and $\mathrm{pH}$ on the rate of transport of silica to the magnesia. In order to accomplish this, it was first necessary to determine whether the 


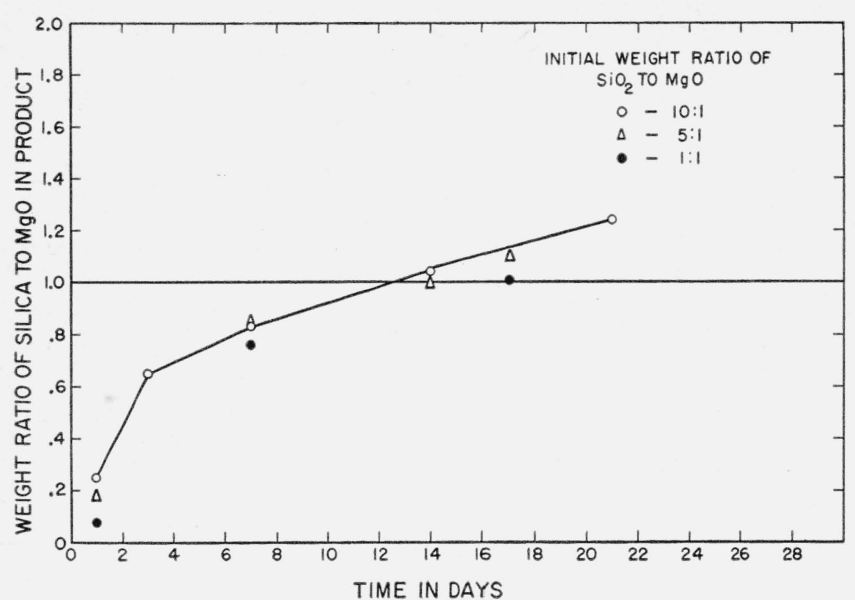

Figure 2. Effect on silica transport of varying the initial ratio of silica to magnesia.

results were reproducible. This was found to be the case, within reasonable limits, provided all (xperimental conditions were fixed. Results obtained in one furnace did not always agree with those obtained in a different furnace. Specifically, two of the furnaces were found to give results differing widely from all the others. This is believed to be due to a difference in temperature gradient. In the majority of the furnaces the temperature at the base of the bomb was found to be about $2 \mathrm{deg}$ higher than that at the top. The two exceptions mentioned above appeared to have a slight gradient in the opposite direction. In these, the transport of silica was negligible. The data recorded below represent experiments in five furnaces giving reasonably concordant results.

\section{d. Effect of proportion of oxides.}

A temperature of $380^{\circ} \mathrm{C}$ was arbitrarily chosen and a series of determinations made, using the apparatus and techniques described earlier. Using three initial proportions of silica to magnesia, namely, 10 to 1,5 to 1 , and 1 to 1 , and in all cases, $4 \mathrm{~g}$ of water in the bombs, the amount of silica transported to the magnesia was determined at various times. The results obtained are shown in table 3 and figure 2.

The spread of the values shown in figure 2 is within the limits of experimental error, and it is therefore concluded that, providing a certain minimum amount of silica is present, the transport of silica to magnesia is independent of the relative amounts of silica and magnesia. The amount of silica used in all cases was sufflcient to cover the bottom of the bomb. It may be that the available surface area of the silica is a significant factor, but this was not investigated. It was observed that the smaller the absolute amount of silica initially present, the greater was the weight percent of it that was transported under the same conditions of temperature and time. This is to be expected.
TABLE 3. Silica-transport isotherms

\begin{tabular}{|c|c|c|c|c|c|c|}
\hline $\begin{array}{c}\text { Experi- } \\
\text { ment }\end{array}$ & Time & $\begin{array}{c}\text { Weight of } \\
\mathrm{SiO}_{2}\end{array}$ & $\begin{array}{l}\text { Weight of } \\
\text { MgO }\end{array}$ & $\begin{array}{c}\text { Initial } \\
\mathrm{SiO}_{2} / \\
\mathrm{MgO} \\
\text { by weight }\end{array}$ & $\begin{array}{l}\text { Weight of } \\
\mathrm{SiO}_{2} \\
\text { transported }\end{array}$ & $\begin{array}{l}\mathrm{SiO}_{2} / \mathrm{MgO} \\
\text { in protuct } \\
\text { by weight }\end{array}$ \\
\hline \multicolumn{7}{|c|}{ (1) $360^{\circ} \mathrm{C}$ isotherm. Pressure $189 \mathrm{~atm}$. } \\
\hline $\begin{array}{l}1 \ldots \\
2 \ldots \\
3 \ldots \\
4 \ldots\end{array}$ & $\begin{array}{c}\text { Days } \\
2 \\
7 \\
14 \\
21\end{array}$ & $\begin{array}{c}g \\
0.9845 \\
.9874 \\
.9830 \\
.9838\end{array}$ & $\begin{array}{c}g \\
0.0981 \\
.1112 \\
.0789 \\
.0864\end{array}$ & $\begin{array}{r}10.04 \\
8.88 \\
12.46 \\
11.38\end{array}$ & $\begin{array}{c}g \\
0 . \\
.0183 \\
.0400 \\
.0421 \\
.0946\end{array}$ & $\begin{array}{r}0.19 \\
.36 \\
.53 \\
1.09\end{array}$ \\
\hline \multicolumn{7}{|c|}{ (2) $380^{\circ} \mathrm{C}$ isotherm. Pressure $235 \mathrm{~atm}$. } \\
\hline $\begin{array}{l}5 \\
5 \\
6 \\
7 \\
8 \\
9 \\
10 \\
11 \\
12 \\
13 \\
14 \\
15 \\
16 \\
17 \\
18 \\
19 \\
20 \\
21\end{array}$ & $\begin{array}{r}1 \\
1 \\
1 \\
1 \\
3 \\
7 \\
7 \\
7 \\
7 \\
14 \\
14 \\
14 \\
14 \\
21 \\
21 \\
21 \\
28\end{array}$ & $\begin{array}{r}1.0036 \\
.9994 \\
.100 \\
.500 \\
1.0000 \\
1.0038 \\
.5036 \\
.1022 \\
.4834 \\
1.000 \\
.5052 \\
1.000 \\
1.000 \\
1.0007 \\
.100 \\
.500 \\
.9961\end{array}$ & $\begin{array}{c}0.1046 \\
.100 \\
.1150 \\
.0965 \\
.100 \\
.1027 \\
.100 \\
.100 \\
.100 \\
.1077 \\
.100 \\
.0960 \\
.0965 \\
.1060 \\
.0994 \\
.0990 \\
.0933\end{array}$ & $\begin{array}{r}9.59 \\
9.99 \\
.87 \\
5.18 \\
10.00 \\
9.77 \\
5.04 \\
1.02 \\
4.83 \\
9.29 \\
5.05 \\
10.42 \\
10.39 \\
9.44 \\
1.01 \\
5.05 \\
10.67\end{array}$ & $\begin{array}{c}0.0267 \\
.0265 \\
.0080 \\
.0170 \\
.0650 \\
.0848 \\
.0851 \\
.0760 \\
.0945 \\
.1078 \\
.100 \\
.1085 \\
.1006 \\
.1311 \\
.0971 \\
.1130 \\
.1597\end{array}$ & $\begin{array}{r}0.25 \\
.26 \\
.08 \\
.18 \\
.65 \\
.83 \\
.85 \\
.76 \\
.94 \\
1.00 \\
1.00 \\
1.13 \\
1.04 \\
1.24 \\
.98 \\
1.10 \\
1.71\end{array}$ \\
\hline \multicolumn{7}{|c|}{ (3) $400^{\circ} \mathrm{C}$ isotherm. Pressure $274 \mathrm{~atm}$. } \\
\hline $\begin{array}{l}22 \\
23 \\
21 \\
25 \\
26 \\
27 \\
28 \\
29 \\
30\end{array}$ & $\begin{array}{r}1 \\
3 \\
8 \\
8 \\
8 \\
12 \\
14 \\
14 \\
21 \\
\end{array}$ & $\begin{array}{l}0.9940 \\
.9995 \\
1.000 \\
1.000 \\
.9757 \\
1.000 \\
1.000 \\
.9963 \\
1.000\end{array}$ & $\begin{array}{r}0.0892 \\
.0909 \\
.0988 \\
.1067 \\
.0960 \\
.1052 \\
.0957 \\
.0934 \\
.0957\end{array}$ & $\begin{array}{r}11.14 \\
11.00 \\
10.12 \\
9.37 \\
10.16 \\
9.51 \\
10.45 \\
10.66 \\
10.45\end{array}$ & $\begin{array}{r}0.0107 \\
.0304 \\
.0837 \\
.0864 \\
.0564 \\
.1092 \\
.1118 \\
.1183 \\
.1434\end{array}$ & $\begin{array}{r}0.12 \\
.33 \\
.85 \\
.81 \\
.59 \\
1.04 \\
1.17 \\
1.26 \\
1.50\end{array}$ \\
\hline \multicolumn{7}{|c|}{ (4) $420^{\circ} \mathrm{C}$ isotherm. Pressure $312 \mathrm{~atm}$. } \\
\hline $\begin{array}{l}31 \\
32 \\
33 \\
34 \\
35\end{array}$ & $\begin{array}{r}3 \\
9 \\
14 \\
21 \\
21\end{array}$ & $\begin{array}{r}0.9628 \\
.9833 \\
.9849 \\
1.000 \\
1.000\end{array}$ & $\begin{array}{r}0.0987 \\
.0930 \\
.0968 \\
.1037 \\
.0970\end{array}$ & $\begin{array}{r}9.75 \\
10.57 \\
10.17 \\
9.64 \\
10.31\end{array}$ & $\begin{array}{r}0.0328 \\
.1091 \\
.1385 \\
.1553 \\
.1583\end{array}$ & $\begin{array}{l}0.33 \\
1.17 \\
1.43 \\
1.50 \\
1.63\end{array}$ \\
\hline
\end{tabular}

It was further observed that, within the limits of these experiments, the identities of the reaction products of the magnesia and the transported silica were not a function of the initial proportions of silica and magnesia. These reaction products are discussed later.

Effects of time and temperature. Four temperatures were arbitrarily chosen, namely, $360^{\circ}, 380^{\circ}, 400^{\circ}$, and $420^{\circ} \mathrm{C}$, and determinations were made of the silica transported to magnesia after $3,7,14$, and 21 days at each of these temperatures.

The initial proportion of silica to magnesia was 10 to 1 in each case, and the bomb contained $4 \mathrm{~g}$ of water. Because the amount of water used was constant, the pressures that obtained in the bombs varied with the temperature and also in the case of the postcritical temperatures with the ratio of the volume of water to that of the bomb cavity. The bombs used were fairly uniform in capacity, and for this work were considered identical. Each isotherm then had its own characteristic pressure. These pressures were, for the four temperatures of $360^{\circ}, 380^{\circ}, 400^{\circ}$, and $420^{\circ}$, respectively, 189,235 , 274 , and $312 \mathrm{~atm}$. 


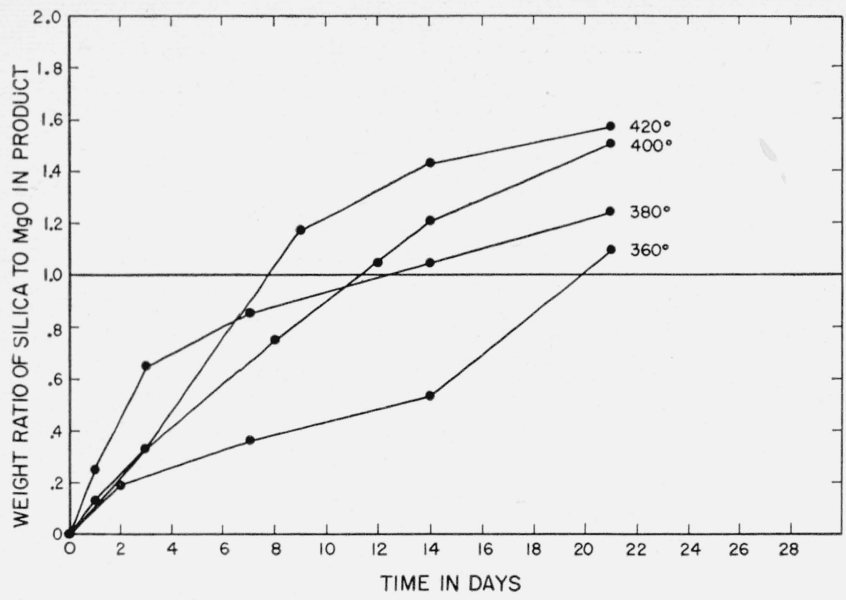

Figure 3. Silica transport at various temperatures.

The data obtained from these experiments are presented in table 3 and figure 3 . In figure 3 it may be observed that the amount of silica transported increases with increasing time at each temperature and that it increases with increasing temperature. It may further be observed that the three postcritical isotherms are of the same type, showing rapid early transport of silica relative to the transport at the one precritical temperature. The identity of the reaction products between the magnesia and the transported silica is not a function of temperature in this range. These will be discussed later.

Effect of pressure. A temperature of $420^{\circ} \mathrm{C}$ and a time of 14 days were arbitrarily chosen to study the effect of pressure on silica transport. The same apparatus and techniques previously described were used. The pressure was varied from 15 to $600 \mathrm{~atm}$ by varying the degree of filling of the bomb with water. The actual values of the pressure under these varying circumstances were obtained by interpolation in the tables given by Van Nieuwenburg and Blumendal [7]. It was found that at pressures above $330 \mathrm{~atm}$, in the particular equipment that was used, the transport of extraneous material from the bombs and metal gaskets made it impossible to obtain quantitative data. For this reason, data obtained at pressures above $330 \mathrm{~atm}$ are not included in this report.

The results of these determinations are presented in table 4 and figure 4 . Referring to figure 4 , it may be observed that the amount of silica transported at $420^{\circ} \mathrm{C}$ increases with increasing pressure, gradually at first, then very rapidly in the pressure range of 200 to $300 \mathrm{~atm}$, after which it begins to level off.

The distribution and proportions of the reaction products depend on the amount of silica transported and consequently on pressure, temperature, and time, but the identity of these products is not a function of these variables in the ranges investigated.

These reaction products were examined with the petrographic microscope, and X-ray powder patterns were made of samples taken from different depths in

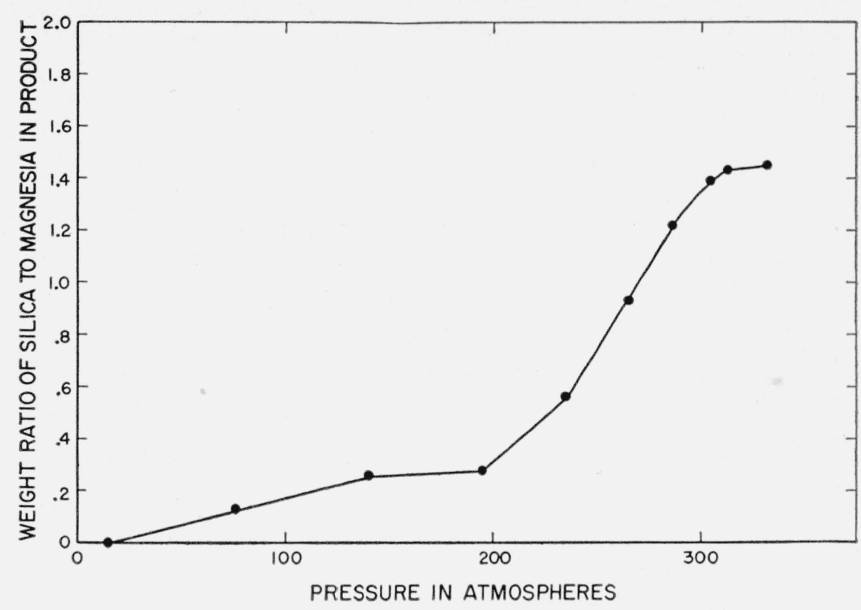

FIgURE 4. Effect of pressure on silica transport at a constant temperature of $420^{\circ} \mathrm{C}$ and a contsant time of 14 days.

TABLE 4. Effect on silica transport of varying the pressure at consiant temperature of $420^{\circ} \mathrm{C}$ and constant time of 14 days

\begin{tabular}{|c|c|c|c|c|c|c|c|}
\hline $\begin{array}{l}\text { Experi- } \\
\text { ment }\end{array}$ & $\begin{array}{l}\text { Weight } \\
\text { of silica }\end{array}$ & $\begin{array}{l}\text { Weight } \\
\text { of MgO }\end{array}$ & $\begin{array}{l}\text { Initial } \\
\mathrm{SiO}_{2} / \\
\mathrm{MgO}, \mathrm{by} \\
\text { weight }\end{array}$ & $\begin{array}{l}\text { Weight } \\
\text { of } \mathrm{H}_{2} \mathrm{O}\end{array}$ & Pressure & $\begin{array}{c}\text { Weight } \\
\text { of silica } \\
\text { trans- } \\
\text { ported }\end{array}$ & $\begin{array}{c}\mathrm{SiO}_{2} / \\
\mathrm{MgO} \text { in } \\
\text { product, } \\
\text { by } \\
\text { weight }\end{array}$ \\
\hline $\begin{array}{l}1 \ldots \\
2 \ldots \\
3 \ldots \\
4 \ldots \\
5 \\
5\end{array}$ & \begin{tabular}{l|}
$g$ \\
1.1195 \\
1.1100 \\
1.1218 \\
1.0006 \\
1.1108
\end{tabular} & $\begin{array}{l}g \\
0.1072 \\
.1142 \\
.0899 \\
.0910 \\
.0903\end{array}$ & $\begin{array}{l}12.19 \\
12.61 \\
12.58 \\
10.99 \\
12.64\end{array}$ & $\begin{array}{c}g \\
0.10 \\
.50 \\
1.00 \\
1.00 \\
1.50\end{array}$ & $\begin{array}{r}\text { atm } \\
15 \\
76 \\
140 \\
140 \\
195\end{array}$ & \begin{tabular}{c|}
$g$ \\
0.0002 \\
.0145 \\
.0216 \\
.0253 \\
.0246
\end{tabular} & $\begin{array}{r}0.00 \\
.13 \\
.24 \\
.28 \\
.27\end{array}$ \\
\hline $\begin{array}{l}6 \ldots \ldots \\
7-\ldots \\
8-\ldots . . . \\
9 \ldots \ldots \\
10 \ldots\end{array}$ & $\begin{array}{r}1.1360 \\
0.9694 \\
.9735 \\
.9993 \\
.9849\end{array}$ & $\begin{array}{l}.0976 \\
.1040 \\
.0990 \\
.0960 \\
.0968\end{array}$ & $\begin{array}{r}12.25 \\
10.05 \\
8.03 \\
10.41 \\
10.17\end{array}$ & $\begin{array}{l}\text { 2. } 00 \\
\text { 2. } 50 \\
\text { 3. } 00 \\
\text { 3. } 50 \\
\text { 4. } 00\end{array}$ & $\begin{array}{l}234 \\
266 \\
286 \\
303 \\
312\end{array}$ & $\begin{array}{l}.0552 \\
.0964 \\
.1212 \\
.1335 \\
.1385\end{array}$ & $\begin{array}{r}.56 \\
.93 \\
1.22 \\
1.39 \\
1.43\end{array}$ \\
\hline $\begin{array}{l}11 \ldots \\
12\end{array}$ & $\begin{array}{r}.9985 \\
1.1300\end{array}$ & $\begin{array}{l}.1053 \\
.1056\end{array}$ & $\begin{array}{r}9.48 \\
12.35\end{array}$ & $\begin{array}{l}5.00 \\
5.00\end{array}$ & $\begin{array}{l}332 \\
332\end{array}$ & $\begin{array}{l}.1555 \\
.1493\end{array}$ & $\begin{array}{l}1.48 \\
1.41\end{array}$ \\
\hline
\end{tabular}

the platinum thimble containing the charge. Only three compounds were formed, namely, chrysotile, talc, and brucite.

In general, talc predominated in the silica-rich surface of the reaction product, and its proportion increased with increasing amount of silica transported. The chrysotile occurred as microcrystals visible under the electron microscope only, but giving a sharp X-ray diffraction pattern. Brucite always predominated in the bottom half of the reaction product and sometimes also in the upper half, depending on the amount of silica that had been transported. In the investigation of effect of pressure at $420^{\circ} \mathrm{C}$, it was found that the proportion of talc and chrysotile in the bottom half of the reaction product was greater at lower pressures.

Effect of $\mathrm{pH}$. The effect of increasing the $\mathrm{pH}$ on the transport of silica to magnesia was investigated at $420^{\circ} \mathrm{C}$ and a constant period of 14 days. In each case the proportion of silica to magnesia initially present was 10 to 1 , the absolute amounts being 1 and $0.1 \mathrm{~g}$, respectively, and the amount of water present was $4 \mathrm{~g}$. 
The $\mathrm{pH}$ was not measured as such but was varied by adding increasing proportions of $\mathrm{NaOH}$ to the silica initially present. The experiments were otherwise identical with those previously described. It was found that the transport of silica was not affected until the molar ratio of $\mathrm{NaOH}$ to silica initially present was about 0.15 and that the amount of silica transported thereafter increased with increasing $\mathrm{NaOH}$. When the initial $\mathrm{NaOH}$ to silica molar ratio was 0.32 , the amount of silica transported had increased about 64 percent over what was transported under the same conditions without any $\mathrm{NaOH}$ being present.

The $\mathrm{NaOH}$ appeared to have no effect on the reaction product other than what could be expected by increasing the amount of silica transported, that is, increasing the proportion of talc.

Because of experimental difficulties involved in accurately weighing $\mathrm{NaOH}$ and because $\mathrm{pH}$ cannot be directly measured under these conditions, only a few determinations were made.

Effect of calcium present as an impurity. During some preliminary experiments on this method of synthesis, a new crystalline product was observed, and the same material was found in minute quantities in a considerable number of later preparations. It consisted of slender, flexible fibers, occasionally $2 \mathrm{~mm}$ or more in length. The refractive indices, 1.584 to 1.594 , were somewhat higher than those usually given for chrysotile, although the values found in the literature vary over a wide range. Because of the possibility that these crystals might be chrysotile, a great deal of work was done in an attempt to increase the yield. At the same time, it was suspected that the fibers might prove to be the hydrated calcium silicate, xonotlite, because the refractive indices were about right for this compound. Addition of small quantities of lime to the magnesia appeared to have no effect. However, an increased yield of the fibrous crystals was obtained by substituting dolomitic lime for the magnesia, but the amount was still too small for identification. After much futile experimentation, a product was obtained containing a few tenths of a milligram of the fibrous crystals, which could be separated mechanically from the rest of the material. X-ray analysis proved them to be xonotlite. Although it was known that the magnesia contained some calcium (equivalent to 0.17 percent of $\mathrm{CaO}$ ), the amount of the latter was so slight that the formation of calcium silicate crystals of conspicuous size was somewhat surprising. It was estimated that the calcium must have been quantitatively converted in order to account for the amount of xonotlite produced.

Miscellaneous experiments. The experiments discussed above were designed to bring out in a systematic manner the effects of varying certain experimental conditions. A variety of other experiments were performed, in a qualitative way, in an attempt to promote the growth of crystals of chrysotile of larger size. For example, the magnesia was made into a paste and coated on the crucible or on other supports of various shapes. Again, the period of hydrothermal treatment was increased to 45 days. Traces of various acids and of compounds of various metals were added, both to the silica and to the magnesia. In no case were any microscopically visible crystals of chrysotile produced.

Silica in the vapor phase was found to react with magnesium carbonate at $380^{\circ} \mathrm{C}$, with formation of chrysotile and talc. Natural serpentine was partially altered to talc by exposure to siliceous vapor for 7 days at $380^{\circ}$, but not at $350^{\circ}$. Under similar conditions, at $380^{\circ}$, olivine showed evidence of surface attack.

In another series of four experiments, an attempt was made to increase the size of fragments of natural chrysotile asbestos fibers. Bundles of fibers were cut to a length of about 0.03 inch and treated hydrothermally under four conditions: (a) on the surface of a bed of $\mathrm{MgO}$; (b) imbedded in $\mathrm{MgO}$; (c) imbedded in a mixture of $\mathrm{MgO}$ and $\mathrm{SiO}_{2}$ in 3:2 ratio; (d) packed into cavities in magnesite. Treatment was for 14 days at $420^{\circ} \mathrm{C}$, with $3 \mathrm{~g}$ of water in the bomb; other conditions were as described previously for the vapor-transport experiments. No change in the size or appearance of the chrysotile fibers was observed.

\section{Summary}

Magnesia and silica in 3:2 ratio were found to combine under hydrothermal conditions at temperatures as low as $200^{\circ} \mathrm{C}$. X-ray and electron microscope studies showed that the product was chrysotile, but the fibrous crystals were too small to be distinguished as such by light microscopy.

Chrysotile, together with talc, was also formed by the action of siliceous vapor on magnesia. Conditions governing the rate of transport of the silica were worked out in considerable detail. The rate was found to increase with temperature and pressure and also with the initial $\mathrm{pH}$. No improvement in crystal size resulted from this method of synthesis.

Silica was found to displace $\mathrm{CO}_{2}$ from $\mathrm{MgCO}_{3}$ under hydrothermal conditions at $380^{\circ}$.

The X-ray diffraction patterns were prepared by B. M. Sullivan and G. M. Ugrinic, of the Constitution and Microstructure Section. Their valuable assistance is acknowledged with thanks.

\section{References}

[1] N. L. Bowen and O. F. Tuttle, Bul. Geol. Soc. Am. 60, 439 (1949).

[2] J. K. Gjaldbaek. Z. anorg. Chem. 144, 145 (1925).

[3] A. Travers and Nouvel, Compt. rend. 188, 499 (1929)

[4] E. P. Flint, H. F. McMurdie, and L. S. Wells, J. Research NBS 21, 617 (1938) RP1147.

[5] F. V. Syromyatnikov, Econ. Geol, 30, 89 (1935).

[6] C. J. van Nieuwenburg, Rev. gen. sci. appl. (Brussels) 1, $61(1952)$.

[7] C. J. van Nieuwenburg and H. B. Blumendal, Rec. trav. chim. 51, 707 (1932).

Washington, July 16, 1953. 